Article

\title{
Empirical Evidence Illuminating Gendered Regimes in UK Higher Education: Developing a New Conceptual Framework
}

\author{
Paula Burkinshaw ${ }^{1}$, Jane Cahill 2 (D) and Jacqueline Ford ${ }^{2, *}$ \\ 1 Leeds University Business School, Leeds LS2 9JT, UK; p.burkinshaw@leeds.ac.uk \\ 2 School of Healthcare, University of Leeds, Leeds LS2 9JT, UK; j.l.cahill@leeds.ac.uk \\ * Correspondence: jacqueline.ford@durham.ac.uk
}

Received: 26 February 2018; Accepted: 25 May 2018; Published: 5 June 2018

\begin{abstract}
Debates on the absence of women in senior organizational roles continue to proliferate but relatively little attention is paid to the Higher Education (HE) context in which women in leadership roles are seriously under-represented. However, higher education is now central to UK political discourse given the growing controversy around student fees, vice chancellors' remuneration' and Brexit. This paper draws on a collaborative research study on the experiences of 105 senior women leaders across 3 UK Universities, which elicited accounts of constraints, successes and career highlights. Our research findings present empirical insights that expose the continuing gender inequalities most notable in senior Higher Education roles. Women's accounts include stories of diverse experiences, on-going discriminatory practices and a failure to recognise the embedded gendered inequalities that continue to prevail in these institutions. Through a critical interrogation of the narratives of female professors and building on insights from a seminal paper by Broadbridge and Simpson a conceptual framework is offered as a heuristic device to capture critical and reflexive data in future studies of equality and inequality in leadership roles.
\end{abstract}

Keywords: gender inequalities; leadership; higher education; ambiguity; difference; Gender; Equity/social justice

\section{Introduction}

'So by populating senate ... populating any other committee in an ex officio [capacity] ... wouldn't it be better just to write a constitution for two white men because that's what you are going to get'

[Lucy, University X]

Lucy is voicing her concerns during a seminar held within a collaborative funded research project across three UK universities that sought to gather female professors' narratives on why there remains a shortfall of senior women in their institutions-a pattern that seems to be mirrored across the UK. Lucy describes the populating of university committees by ex officio appointments- we have cited it as an illustrative example of a common institutional practice, reflective of masculinities cultures. Such a cultural backdrop perpetuates dominant masculine norms of leadership, leads to a continuing tendency to promote men and presents a striking antidote to plurality and difference reflecting entrenched gendered regimes. Plurality and difference are global concepts and in this study we use them to denote an openness to diversity in viewpoints, beliefs and their interpretation including an openness to ambiguity and dissonance. These are concepts which underpin our study and which we harness in an effort to counter gendered regimes and hierarchies, meaning the interlocked processes 
and practices that result in gender inequalities across UK higher education. This concept of gendered regimes is illuminated throughout our work.

It may seem counter-intuitive to begin a paper (concerned as it is with ideas around plurality and difference) with a quote depicting a dystopian world in which diversity is abandoned by a valorisation of masculine norms. However this encapsulates our inductive data-driven approach in which we listen to participants' voices, and seek to make sense of multiple experiences. Attending to colliding and conflicting views ensures that the principles of plurality and difference are woven into the fabric of our research and resulting recommendations. Our contribution is two-fold. Firstly, we offer empirical insights that illuminate the complexity, uncertainty and tensions in women's working lives, exposing career barriers and accounts of limited success,. Secondly, we extend the work of Broadbridge and Simpson [1] proposing a lconceptual framework to support and capture future research on gender, plurality and difference in HE.

\section{Rationale for the Research}

Women are seriously under-represented at leadership levels in UK HE with current data indicating that a mere $21 \%$ of the professoriate and $22 \%$ of vice chancellors are female [2,3]. These stark data sit within the context of an estimated 5400 'missing women' from senior appointments across UK society [4]. The reported shortfall of senior women in the corporate sector led to the Davies review (2010) which established a target of $25 \%$ of non-executive directorships to be held by women in UK FTSE 100 companies by the end of 2015. This review triggered a number of high profile initiatives to redress gender inequality in leadership roles across all sectors of the UK economy including politics, businesses more broadly, the public sector, and the legal profession. It is perhaps ironic that the HE sector appears to be lagging behind the reported progress in other sectors. Furthermore, whilst women are predicted to form the majority of all academics in junior and middle level posts by 2020, they will not be equally represented at professorial level until 2070 at the earliest [4,5]. Such projections present one of the drivers to pursue this collaborative research project, which has the potential for being extended across the HE sector both nationally and internationally.

Equality is arguably a cornerstone of HE philosophy and enlightenment. As such it matters that the sector embraces gender equality and is seen to be addressing the 'missing women' conundrum [6]. Not only does HE contribute $£ 73$ billion to the economy, it also receives billions from public funding bodies who in turn must demonstrate they satisfy equalities legislation [7]. Moreover, the shortfall of women in senior roles in HE has wider and more serious consequences for women's participation in public life [8]. Women's leadership at board level and in executive roles continues to be under the spotlight across all segments of society and the economy. The topic is "critical for HEIs who create economic benefit through knowledge and innovation and educate future leaders. How they lead and perform on this issue matters, given the pivotal role they play" (p. 5) [3]. It is noteworthy that policy bodies across the sector are collaborating to promote their ambition for gender equality so as to influence policies and practices in HE. Indeed, institutions were mandated by HEFCE to go beyond a mere declaration of the gender profile of staff and students through reporting specific action to improve the gender balance of their leadership teams (November 22, 2015). This is further indication of the timeliness for the academic community to invest in research on gender inequality in HE leadership [9]. The authors acknowledge that leadership and gender may have multiple meanings across different contexts including and within higher education.

The paper is structured as follows. It begins with a review of the context for change, focusing on a range of drivers currently operating within HE. Next the review of the literature is organised around the conclusions from Broadbridge and Simpson's paper [1] with particular attention to recent developments in HE. The methods section explains our approach to the empirical research, and is followed by the framing (and interrogation) of our research findings within the conceptual framework. Finally, the discussion explores a more reflexive, critical appraisal of the significance and contribution of the study findings. 


\section{The Context for Change}

A number of drivers for change to the current workforce gender profile within the UK academic community have surfaced; firstly, the Research Councils UK (RCUK) positioning on the Athena Swan Charter, as articulated in the RCUK expectations for equality and diversity (17th January, 2013). The Athena Swan charter is a UK national initiative committed to advancing women's careers in science, technology, engineering, mathematics and medicine (STEMM) in HE and research. In a letter to the Medical Schools Council, July 2011, the Chief Medical Officer Professor Dame Sally Davies announced that the National Institute for Health Research (NIHR) would only shortlist medical schools for biomedical research centre and unit (BRC/BRU) funding which held a Silver Athena SWAN Award (This stipulation, effective from March 2017, is therefore providing significant impetus for medical schools to engage with the charter. Silver status is evidence of an institution's ability to evidence impact of good gender equality practice. Although medical schools are most directly impacted, the uptake of the Athena Swan charter has been expressed across STEMM departments. Since its establishment in 2005, 132 institutions across the UK have signed up to the charter and 463 departments have gained awards. Such an award, at the minimum standard of silver status entitles award holders to apply for research funding. In May 2015, the scope of the Charter was both extended and broadened to include the arts, humanities, social sciences, business and law as well as professional and support roles for staff and students. The impact of these changes has yet to percolate across the sector but it will inevitably demand a greater focus on the academic profiles of women in HE roles.) More recently the Athena SWAN charter has been extended into other disciplines such as business and humanities too. Similarly 'gender mainstreaming' is taking purchase in the UK HE sector, a process whereby institutions appraise their emerging equality policies and procedures through their impact on improving gender equality. Although necessarily bureaucratic, these measures appear to make a difference by highlighting often unintended inequalities and outcomes [10,11].

A second powerful driver for change is the sector's substantive contribution to the economy: through its unique position in creating and disseminating knowledge, HE is not only highly visible but also carries social, economic, scientific and cultural responsibilities $[3,6]$. Thus, the under-representation of senior women is a fundamental issue for UK society which has wider and more serious resonance for economic, political and social justice reasons [12]. A further four compelling drivers in favour of promoting gender equality in HE leadership are: the quality and talent gap [13] generated by qualified and competent women being over-looked for high quality leadership, research and teaching opportunities; the business case [14,15] which recognise that universities (and all organisations) perform better and are more successful with gender balanced senior teams; social justice arguments that challenge gender injustice and value diversity and inclusivity $[9,16]$; and equity and parity $[3,6]$ leading calls for pay and other benefits that are non-discriminatory. These contentious drivers are generic to all sectors within and beyond education and shape contemporary conversations on the under representation of women at the top of [17].

Despite such drivers for change, an analysis of academic literature indicates that the structure, culture and hierarchical regimes of academia continue to reproduce a particular system of gender relations which privileges both men and masculine ways of behaving [18,19]. To such an extent that despite 'the growing body of theoretical and empirical studies on gender, work and organisations [universities] turn a deaf ear and a blind eye to the developed insight when it comes to their organising processes and principles' (p. 195) [20]. More than a decade later, recent findings that universities continue to ignore the empirical evidence are persuasive factors for reform [21,22]. There is now a significant body of research that indicates that gendered cultures within HE play a fundamental role in shaping academic careers [23]. The following sections draw on relevant literature, framed within the Broadbridge and Simpson review [1] and expanded to include recent studies. In summary, the Broadbridge and Simpson thematic review (see Table 1 below) serves as a useful heuristic enabling us to organise, update and interpret the development of knowledge and insights into gender and organisational research and to locate the contribution of our study within the HE sector. 
Table 1. Broadbridge and Simpson insights.

\begin{tabular}{|c|c|c|c|c|c|c|c|}
\hline \multicolumn{2}{|c|}{$\begin{array}{c}\text { Broadbridge and Simpson: } \\
\text { Developments }\end{array}$} & \multicolumn{2}{|c|}{$\begin{array}{l}\text { Broadbridge and Simpson: } \\
\text { Challenges }\end{array}$} & \multicolumn{2}{|c|}{ Broadbridge and Simpson: Futures } & \multicolumn{2}{|c|}{$\begin{array}{l}\text { Broadbridge and Simpson: } \\
\text { Conclusions }\end{array}$} \\
\hline 1 & $\begin{array}{l}\text { Women's } \\
\text { Voice } \\
\text { Literature }\end{array}$ & 1 & $\begin{array}{l}\text { Problem of gender } \\
\text { has not been solved }\end{array}$ & 1 & $\begin{array}{l}\text { Research must } \\
\text { monitor gender } \\
\text { difference to inform } \\
\text { policy \& practice }\end{array}$ & 1 & $\begin{array}{l}\text { Challenges of } \\
\text { gender denial }\end{array}$ \\
\hline 2 & $\begin{array}{l}\text { Salience of } \\
\text { gendered } \\
\text { cultures }\end{array}$ & 2 & $\begin{array}{l}\text { Diversity and } \\
\text { silencing of } \\
\text { women's voices }\end{array}$ & 2 & $\begin{array}{l}\text { 'Tease out' and } \\
\text { conceptualize } \\
\text { emerging gendered } \\
\text { hierarchies }\end{array}$ & 2 & $\begin{array}{l}\text { Gendered } \\
\text { hierarchies } \\
\text { becoming more } \\
\text { rather than less } \\
\text { entrenched }\end{array}$ \\
\hline 3 & $\begin{array}{l}\text { Remasculinisation } \\
\text { of Management }\end{array}$ & 3 & $\begin{array}{l}\text { Researching men } \\
\text { and masculinities in } \\
\text { management }\end{array}$ & 3 & $\begin{array}{l}\text { To reveal hidden } \\
\text { aspects of gender } \\
\text { and the processes of } \\
\text { concealment within } \\
\text { norms practices } \\
\text { and values }\end{array}$ & 3 & $\begin{array}{l}\text { Challenge notion } \\
\text { that gender } \\
\text { discrimination is } \\
\text { a 'thing of the past' }\end{array}$ \\
\hline 4 & $\begin{array}{l}\text { Gender as a } \\
\text { performance } \\
\text { or doing 'turn' }\end{array}$ & 4 & $\begin{array}{l}\text { Discourses of merit } \\
\text { and choice }\end{array}$ & & & 4 & $\begin{array}{l}\text { Responsibility for } \\
\text { BJM to publicise } \\
\text { outcomes, debates } \\
\text { and emergent } \\
\text { theoretical frames }\end{array}$ \\
\hline
\end{tabular}

\section{The Literature}

\subsection{Women's Voice Literature}

'Women's voice' literature is still influential today. In its key aims of redressing the long-standing neglect of gender in organizational and management research, the emphasis on accounts of women's experiences and the need to incorporate women's interests and values, this approach has increasing purchase in the HE context. There is growing recognition across feminist scholarship that women's voices especially in senior leadership HE echelons have been largely absent and consequently silenced $[17,24,25]$. The recent methodological trend in favour of qualitative research has led to research on the everyday lived experiences of women working in HE. Such studies usually feature in-depth, small-scale semi structured interviews with women in a variety of leadership roles $[17,26,27]$ and this research affords the opportunity to promote personal accounts of women's experiences of gendered leadership cultures within HE. Their stories reveal the effect of masculine cultures and it is these accounts that seek to dispel the myth of gender neutrality [18]. Such findings resonate with other studies Ford and Harding [28] observe that women report feeling silenced, ridiculed, seduced, subordinated and infantilised by the on-going patriarchal and masculine cultures that are hostile to women. The literature on women's voices also illustrates how the concept of meritocracy further upholds the myth that women can compete for jobs on the same footing as their male counterparts [25].

Despite the increasing 'visibility' accruing from the purported feminisation of HE $[5,24,25]$ masculine norms of leadership continue to thrive. What needs to be considered, and where women's voice literature is perhaps critical, is in the 'weight' accorded to women's voices as 'representation' is not just about an increase in numbers but also the opportunity to speak. Methodologies attesting to the importance of women's lived experiences have potential to increase the scope for cultural and political change.

So the benefit of publicising women's stories lies in their ability to challenge the masculine construction of leadership in HE and to expose the degree to which masculine leadership cultures have resulted in the creation of 'undoable jobs' for women (and men) [27]. Accordingly, more recent research has moved away from blaming women for their absence from these undoable jobs towards a recognition that their under-representation stems from their ongoing resistance to how senior roles play out within gendered leadership cultures [29]. In this sense women's voice literature becomes an explicitly political and transformational act [30]. 


\subsection{Salience of Gendered Cultures}

The power of organisational structures and processes to shape women's experiences in management and leadership roles remains a prominent theme in much research within management and organizational studies [1,31]. Furthermore, there is a body of research which argues strongly that organisational cultures are not only gendered but also gendering [32-34]. Karatas-Ozkan and Chell [35] help explain the notion of gendering by describing gender as:

A powerful ideological device, which is produced and reproduced in social situations as the interactional scaffolding of social structure and the social control processes that sustain it (p.112).

Gendered leadership cultures are also prevalent in HE institutions [36] and they shape academic identities and careers, preventing any easy organizational 'fix' [37]. We know from Broadbridge and Simpson's review that gendered leadership cultures are particularly resilient to equality initiatives $[38,39]$ especially in the era of what has been labelled 'second generation gender bias' (invisible barriers holding back women in organisations) [40]. This resilience is popularised and conceptualised as the 'gendering of excellence' and 'gendered ways of knowing' [41], constructs which help to explain the way HE promotion and recognition practices penalise academics who work collaboratively, dedicate themselves to pastoral work, and emphasise their collegiate responsibilities above individual academic goals and self-interest [42,43]. In this respect attention is turning to the epistemological basis of gendered ways of knowing in an effort to recalibrate society's (and institutions') biases and recognise alternative forms of scholarship [44,45].

Such heightened epistemological awareness has led to moves to address the gendering of excellence and research via 'positive action' (Positive action' refers to the steps that an employer can take to encourage people from groups with different needs or with a past track record of disadvantage or low participation to apply for jobs and is to be distinguished from 'positive discrimination which is illegal in the UK.) measures, which in turn illuminate more apposite interventions. It is argued that through increasing the critical mass of women, the weight of positive action interventions afford a viable alternative to tokenism. It is this critical mass that provides the means to challenge entrenched leadership cultures and to offer alternative leadership models within 'protean organisations', that is organisations that are more fluid and less hierarchical [46,47].

\subsection{Masculinity and Remasculinisation of Leadership and Management}

Individual, institutional and societal issues combine to produce leadership cultures which are defined by masculine norms of leadership whereby the 'ideal employee' (the disembodied worker) thrives $[29,48,49]$. This tends to disadvantage women (and men) who do not easily 'fit in' with hegemonic masculine leadership communities. Despite exaggerated claims of the feminization of leadership, actual practice (and the literature) in the HE sector demonstrates closer signs of the remasculinization (Remasculinization refers to a process whereby practices and processes previously coded (and celebrated as) 'feminine' have been re-shaped and brought into the masculine domain.) of leadership endorsed by an increasing focus on metrics and targets; factors which help to account for the both the ongoing disadvantage and the missing women at the top in HE [50]. In this cultural context, a seemingly gender-neutral human resource procedure and related practice, such as promotion processes, need to be problematized with due recognition of how it reinforces this normative masculine model [51-53]. The accumulated effect of such biases related to the practices of masculinity and remasculinization has the effect of undermining diversity through favouring the status quo and perpetuating a bias against female leaders—or indeed men who favour an alternative approach to the valorised norm. Although raising awareness of gender bias is becoming more commonplace across HE it is recognised that cultural change takes time-indeed the cultural context is arguably the most intractable problem to resolve alongside a range of established and often undetected systemic biases. As a case in point, HE continues to thrive on 'grace and favour' appointments, more often than not culminating from men's relationship with other men [54]. This putative homosociability, an apposite example of remasculinization in its emphasis on interpersonal and relational domains, promulgates 
a 'boys club' culture and furthermore, serves to penalise those who do not, cannot, or choose not to fit in. Consequently masculine norms of leadership as they have been coded, remain out of reach for many ambitious women and men who do not fit these hegemonic norms $[55,56]$.

\subsection{Gender as a Performance}

Broadbridge and Simpson [1] highlight perspectives in which gender is conceptualized as a social practice rather than as a fixed or stable attribute of the individual. Recent qualitative, empirical accounts illuminate the gendering of leadership performances in the academic environment $[17,24,25,57]$ which feeds directly into the construction of academic leadership roles. So, performing a feminine style of leadership excludes women from 'the boys club' yet performing as 'one of the boys' is also frowned upon [58,59]. So invariably leadership roles become constructed as 'undoable' jobs for women [25] in that to be a female leader in HE becomes impossible owing to irreconcilable role violations and conflict. The masculine discourse of academic leadership, reproduced through everyday performances, leads to the inevitable conclusion that if only women became more resilient, more confident, more ambitious and 'more like a man' the problem would be solved [60].

The following sections demonstrate how using our conceptual framework has allowed us both to develop empirical insights and to consider the added value of further themes (and subthemes) which have emerged from our data so as to build on this thematic review.

\section{Epistemology: Employing a Critical Reflexive Lens}

Before presenting our themes and situating them within our framework we outline the methodological approach to our analysis. We employ a critical reflexive lens to interrogate our findings; construct theories; and trouble privileged and hegemonic discourses. Our critical reflexive approach draws on Cunliffe's writing that 'involves examining and unsettling [our italics] our assumptions, actions and their impact, and from a broader perspective what passes as good leadership and management practice' (p. 98) [61]. Focussing on the 'unsettling' of assumptions is both central to our research endeavour and to furthering thinking in the field of gender equality-the questioning of long held assumptions and the opportunity to turn the critical reflexive lens back on ourselves can sometimes be a discomfiting and visceral experience but one that is necessary to encounter our own prejudices. Equally unsettling is the experience of holding a seemingly contradictory position. Critical reflexivity involves putting ourselves into the forefront of the analysis whilst also standing back from our own activities and reflexively questioning each stage of the research process. A commitment to an ongoing reflexive interrogation of previously held truths is also key to advancing growth in revealing processes of concealment within norms, practices and values, and this approach is consistent with our own research practices.

Accordingly our research is located within a constructivist-interpretivist perspective, which seeks to examine female professors' accounts of their working life experiences, constraints and successes in their academic careers. At this juncture we should say that for this reason our sample was explicitly restricted to female professors for the substantive component of the empirical research: the fourteen one-to-one interviews. However we do acknowledge that while this restrictiveness is born out of our research focus - critical interrogation of the narratives of senior academic women-this does of course engender an inherent lack of representativeness in terms of gender and academic background. Furthermore we openly acknowledge that our sample was restricted in terms of racial and ethnic background-all of our interview participants were Caucasian women which does of course limit interpretations to the parameters of our purposive sample which is why our principles of reflexivity (outlined below) are especially pertinent.

Constructivist and critically reflexive thinking seeks to challenge hegemonic assumptions of whole and coherent subjects with a unified sense of identity and a fixed essence, and to draw attention to the shifting, complex and occasionally contradictory subject positions and plurality of subjectivities which surface in our respondents' narratives. Hence, key to this research is the multiplicity and temporality 
of subjectivity; the contextual location and partiality of accounts of the self, and the recognition that our sense of selves 'are inextricably intertwined with context and with the situations in which they are performed, as well as the historic and political discourses and culturally shaped narrative conventions that construct the self' (p. 307) [62].

Many narratives of working lives make evident the intricacies, contradictions and changes which individuals undergo, as well as the multiple strands which interweave to make up individuals' narrated subjectivities [48]. It is not the unambiguous that we seek to study, but rather the breaks, conflicts and contradictions in our research participants' narratives which will ultimately help to challenge normative discourses that perpetuate masculine models of leadership and reconfigure new ones. How people experience and articulate their sense of selves as fluid, shifting and in conflict are tied inextricably into narratives, relations with others, and hegemonic discourses (p.80) [63]. It is through this theoretical perspective that we seek to make sense of how senior women academics navigate the landscape of leadership.

In summary, we sought to challenge, revise and transform predominant ways in which the storied accounts of academic women are constructed. This necessitated an in-depth qualitative approach which captures the subjectively experienced and contextually specific discourses of the senior female academic leaders.

\section{Research Design}

\section{Data Collection}

Data were collected through a multiple qualitative methods approach comprising seminars and workshop events together with interviews with female professors across the three institutions. A total of 105 senior (predominantly female) academics participated in this research study. One-to-one interviews were conducted by authors A and B, each lasting 90-120 min with 14 senior academic women. The interview participants were purposively selected, the selection criteria were that the women be a senior female academic (Professor or equivalent) and to be working at one of the three institutions. All interviews were recorded and transcribed, and participants were provided with a brief overview of the study. The seminars ranged in size between 14 and 40 senior academics at each of the three institutions, addressed an array of issues relating to the aims of the research and were facilitated by varying combinations of the study authors. Table 2 details the title, content, approach and participation used for each of the three institution-based seminars as well as the final dissemination event held at the conclusion to the study. Interviews were guided by life history approaches, which sought to elicit accounts of working lives, career histories and future plans $[29,48,64-66]$ and included a discussion of both career barriers and success stories. Transcripts from all seminar events and individual interviews were analysed through immersion in the data involving close reading and re-readings, resulting in the emergence of several related themes. Narrative methods of analysis were adopted, drawing from McAdams theoretical and methodological approach [64,67].

All study participants were assured of both confidentiality and anonymity and pseudonyms are used throughout this paper. The data from these multiple methods elicited numerous narrative accounts of the experiences, challenges and success stories of these senior academic women as our respondents drew on various, often conflicting and at times paradoxical stories to depict their working lives. 
Table 2. Data collection methods.

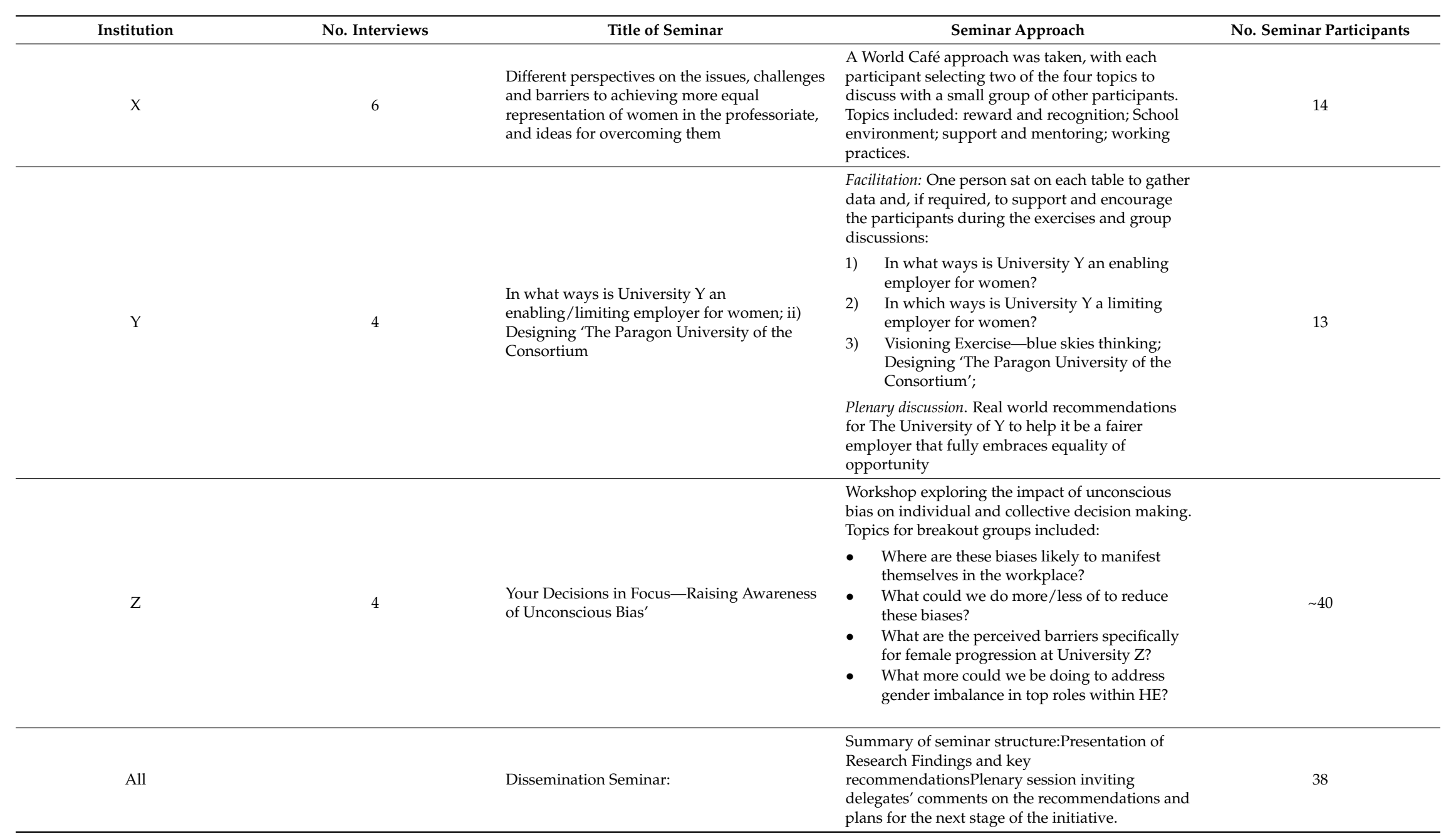




\section{Introducing the Conceptual Framework}

Our underpinning structural framework extends the work of Broadbridge and Simpson's [1] critical review of 25 years of gender and management research. These authors identify four major areas of significant development in research on gender and management: women's voice literature; the salience of gender cultures; remasculinisation of management; and gender as a performance or social practice and these guided our review and update of the literature. In addition Broadbridge and Simpson signpost four challenges, three future research priorities, and four conclusions to shape future contributions from the field. See Table 1 above.

We draw explicitly from these thematic insights in tandem with our analysis of the empirical findings (detailed below) to form a heuristic device which we prefigure here- the conceptual framework presented in Figure 1.

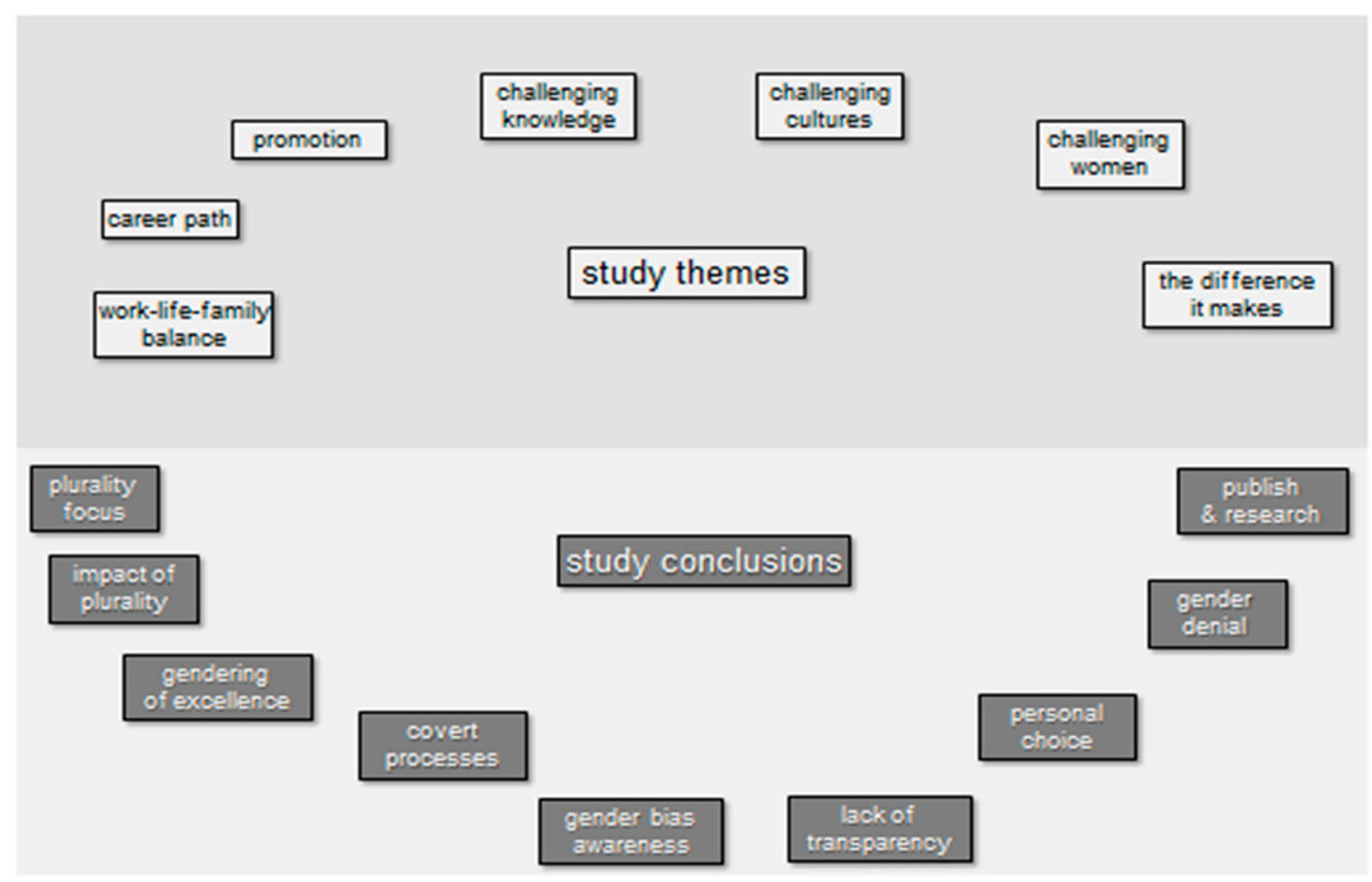

Figure 1. Conceptual framework.

The framework has a two- fold purpose in terms of developing future research studies in the field: first, it lends an organising framework for critical appraisal of the literature; and second, it provides a critical lens through which we and subsequent researchers may examine our empirical findings. With regard to the former, this approach enables us to situate the literature within current debates and to illuminate recurrent themes within the field, as we explore below. It is worth highlighting that whilst these areas have proved an invaluable starting point we have sought to extend their reach into a wider body of knowledge through applying a critical lens to our data and developing fresh empirical insights. A new level of understanding of the gender and leadership literature thus emerges, specifically within the context of HE.

\section{Presentation and Discussion of Empirical Findings}

The study findings and our conclusions have provided the template for our framework (Figure 1). These study findings (summarized in Table 3) emerged from a thematic analysis of the data described above and these seven overarching themes formed the basis for the study conclusions and hence provide the template for our framework (Figure 1). In addition we undertook a mapping exercise 
through which we situated Broadbridge and Simpson's themes within this template to illustrate the degree to which these build upon and develop Broadbridge and Simpson's review. Taken together these form a composite framework. Table 4 explains the mapping process and the subsequent discussion section further develops and elaborates this table through our empirical data.

The advantage of this approach to building a conceptual framework is that it is interactive/ dynamic being contingent on our empirical findings and the unique ways in which they either support, refute or extend the reach of Broadbridge and Simpson's thematic review. Table 3 briefly summarises the study findings and provides an overview of how the data was analysed. We explore these findings more in the discussion and conclusion sections below.

Table 3. Overview of research findings.

\begin{tabular}{|c|c|}
\hline Theme & Description \\
\hline 1. The work-life-family balance conundrum & $\begin{array}{l}\text { Addresses issues relating to work-life balance focusing on tension between } \\
\text { work and family; institutional culture of work life balance and experience of } \\
\text { flexible working arrangements }\end{array}$ \\
\hline 2. The career path-negotiating the trajectory & $\begin{array}{l}\text { Addresses individual career trajectories with a focus on professional and } \\
\text { personal impacts }\end{array}$ \\
\hline $\begin{array}{l}\text { 3. Promotion: ascending the grading structure } \\
\text { and entering the domain of senior leadership }\end{array}$ & $\begin{array}{l}\text { Addresses issues relating to two facets of promotion: progression through } \\
\text { the grades/spine points and professorial zones and acquisition of senior } \\
\text { management and leadership roles within the institution. }\end{array}$ \\
\hline 4. Challenging knowledge and ways of knowing & $\begin{array}{l}\text { Focuses on cultural barriers impacting on female representation in senior } \\
\text { leadership. These are (1) alienating leadership cultures; (2) masculinities } \\
\text { cultures. }\end{array}$ \\
\hline 5. Challenging work and institutional cultures & $\begin{array}{l}\text { Addresses examples of positive institutional culture and positive working } \\
\text { practices }\end{array}$ \\
\hline 6. Challenging women & $\begin{array}{l}\text { Addresses positive and negative impacts on career development that are } \\
\text { perceived to be related to/focused on the individual: (1) } \\
\text { success-individual qualities that have led to professional success; (2) } \\
\text { 'blame'-individual qualities that are perceived to hold women back and } \\
\text { that are perceived to be specific to women; (3) support-supportive } \\
\text { interventions focused on the individual }\end{array}$ \\
\hline 7. The difference it makes & $\begin{array}{l}\text { Focusses on (1) the potential of leadership to impact on future generations } \\
\text { and (2) critical mass arguments focusing on whether growing the diversity } \\
\text { of leadership can fundamentally effect change and policy in HE }\end{array}$ \\
\hline
\end{tabular}

So, what new insights does this research offer? Does it, in the words of the 7th theme, have the potential to make a difference? We share Broadbridge and Simpson's [1] sentiment that only through disseminating key debates are we able to frame and reflect developments in the field. Framing and reflecting is central to this paper-reflecting on the significance of our empirical findings within the emerging conceptual framework we have presented for consideration. In addition to being cognisant of the parameters of the framework we also seek to be mindful of the wider context in which our framework is situated. Accordingly, it may be useful to consider the cultural and academic context of our readership. Currently, themes of plurality abound in the domain of leadership and management research: notwithstanding the current popularity of this concept, it is worth asking what is 'plurality' and why is it capturing the attention of scholars? Maybe some clues are to be found in two key domains of academic activity: conference design and journal publications. With regard to the former, plurality has inspired the titles of two recent conferences, one in management and one in HE. The title of the BAM 2015 conference was 'The Value of Pluralism in Advancing Management Research Education and Practice' and the title of the 2014 SRHE conference was 'Inspiring future generations; embracing plurality and difference in $\mathrm{HE}^{\prime}$. A close reading of the two conference remits suggests that the concept of plurality not only signifies its potential to enrich leadership and management research and to reconfigure HE provision for multiple stakeholders, but is also indicative of a challenging dynamic between plurality and diversity on the one hand and homogeneity and inclusivity on the other. In terms of balancing the dynamic, we believe it is important to encourage diversity in modes of understanding and research practice while ensuring that inclusivity is met by safeguarding equity of opportunity rather than yielding to pressure of homogenization. 
Table 4. Mapping of study findings onto Broadbridge and Simpson categories.

\begin{tabular}{|c|c|c|}
\hline Study Findings & B and S Categories & Study Conclusions \\
\hline $\begin{array}{l}1 \text { Work-life-family balance conundrum } \\
\text { (Ch 4) }\end{array}$ & $\begin{array}{l}\text { Developments }(\mathrm{D}) \\
\text { 1. Women's voice literature }\end{array}$ & 1 Plurality rather than gender focus (Ch1) \\
\hline $\begin{array}{l}2 \text { Career path-negotiating the trajectory } \\
\text { (D2; Ch3) }\end{array}$ & 2. Salience of gendered cultures & 2 Impact of plurality (D3) \\
\hline 3 Promotion (D2; Ch3) & $\begin{array}{l}\text { 3. Masculinity and } \\
\text { remasculinisation }\end{array}$ & 3 Gendering of excellence (D2) \\
\hline $\begin{array}{l}5 \text { Challenging work and institutional } \\
\text { cultures (D3; RP2) }\end{array}$ & Challenges (Ch) & 5 Gender bias awareness training $(\mathrm{C} 2)$ \\
\hline 6 Challenging women (D1; Ch2; Ch4) & $\begin{array}{l}\text { 1. Problem of gender has been } \\
\text { 'solved' }\end{array}$ & 6 Lack of transparency (C2) (RP3) \\
\hline \multirow[t]{11}{*}{7 The difference it makes (Ch1; RP1) } & $\begin{array}{l}\text { 2. Diversity and silencing of } \\
\text { women's voices: dilution of } \\
\text { women's voices through focus on } \\
\text { diversity research }\end{array}$ & 7 Personal choice? (Ch2) \\
\hline & 4. Discourses of merit and choice & 9 Responsibility to publish/research (C4) \\
\hline & Research Priority (RP) & \\
\hline & 1. Inform policy and practice & \\
\hline & 2. Emerging hierarchies & \\
\hline & 3. Reveal covert processes & \\
\hline & Conclusions (C) & \\
\hline & 1. Challenge of gender denial & \\
\hline & 2. More entrenched & \\
\hline & 3. Not thing of the past & \\
\hline & 4. BJM responsibility to publish & \\
\hline
\end{tabular}

With regard to the second domain-journal publications-we observe that at the time of writing this paper one of the popular articles on British Journal of Management is 'The glass cliff: Evidence that women are over-represented in precarious leadership positions' [68]. Given that this paper is over a decade old, this finding is perhaps on one level unremarkable. However, that this article continues to retain a high profile a decade later perhaps indicates that there is something about the issue of gender diversity in leadership that has not been resolved, and which remains very much at the forefront of debates in leadership and management. Our question at this juncture is what can consideration of plurality offer to the advancement of gender diversity? The think crisis-think female gendered expectation figured in the 'glass cliff' paper applies a metaphorical strait jacket to women's careers and reputation as leaders. The following discussion, with recourse to our empirical findings and conceptual framework, explores the (unresolved) questions posed by Broadbridge and Simpson in their conclusions: how gender hierarchies are becoming more entrenched and whether gender discrimination is really a thing of the past.

\subsection{Challenges of Gender Denial, and Gendered Hierarchies Becoming More (Rather than Less) Entrenched}

Broadbridge and Simpson [1] identify continuing challenges in the form of 'gender denial' which is cultivated by processes of concealment, a natural sequel of which is the entrenchment of gendered hierarchies. Our findings emphasize that the absence or even blatant disregard of plurality in HE institutions has been a key player in this process. Our research highlighted two major barriers to female advancement within senior leadership roles in HE: societal (cultural) and institutional barriers. Together these constitute a form of 'gender denial' and are characterised by the trademark side-lining of gender as an issue. Societal (or cultural barriers) are essentially covert in nature; a notable example surfacing in our data is the 'gendering of excellence' whereby merit is defined and rewarded against masculine norms of behaviour. This phenomenon has been more widely noted internationally with documented efforts to deconstruct the criteria of academic excellence [22,52]. The specific issue of promotions criteria is one such illustration of the damage that can occur when plurality does not inform practice, 
leading to unitary cultural biases becoming entrenched, internalised and adopted as default, normative practice. Promotions criteria were observed, across all three institutions, as being predominantly male centric and being driven by a number of unconscious biases lending empirical support to the notion that such forms of gendered hierarchies are becoming more entrenched, facilitated by the 'discourse of meritocracy and choice' [1]. As respondent Yasmin indicates, the conflation of quantitative metrics with inherent value illustrates that the challenge of contesting this patriarchal/normatively masculine vision of excellence involves reintroducing collaborativeness into models of excellence:

'And I think the things that are valued are the things that are easily measured. And it's easy to measure grant income, it's less easy to measure your contribution to making your research team work well, your contribution to running projects well'

\section{(Yasmin, University Z)}

In the plenary session of the dissemination seminar, there was a highly constructive and creative recommendation for a 'rethinking of excellence' programme, which would involve expanding and developing the agreed characteristics of reward and recognition to effect a change to promotions criteria and language. It was recognised that in order for any type of change to be effected in these areas transparency in decision and policy-making was required at institutional level. Karatas-Ozkan and Chell [33] show how at the meso and macro organisational levels our academic institutions 'perpetuate practices that have significant bearings on academic career development' (p. 121). However, institutional transparency alone does not adequately address the primacy of the covert processes played out in promotions procedures [54]. What is needed is a shift in emphasis from addressing overt processes (representation of genders on a promotions panel) to uncover more covert processes such as addressing the mechanisms through which applications are assessed.

The salience of covert processes was a recurrent underpinning feature of many of our study themes. For example at the heart of the 'Work-life-family balance conundrum' is a collective buy in to discourse of merit and choice, aptly termed a key challenge in that it is underpinned by a collective denial:

'I think probably one of the main things about that is that it's really hard to compare CVs when people have had time out. So if you have time out because of maternity leave or leaves, you shouldn't-I really don't think you should expect to move at the same rate'.

(Sue, University Y)

Such an approach within a rethinking of excellence resonates well with teasing out gendered hierarchies and 'revealing' hidden processes of concealment within dominant discourses [1]. While it is possible to characterize overt processes as equitable and transparent, thereby supporting institutional discourses of fairness and meritocracy, the more covert processes (albeit challenging to detect) afford opportunities to effect culture change and resist the dominant discourses that preserve gender inequality. Indeed, the success of initiatives relating to positive practice and positive work culture (study theme 5) can be undermined by deeply held cultural beliefs ingrained in the institutional consciousness. Take for example the popular 'core hours' policy currently championed by Athena Swan initiatives across the UK as a beacon of excellent practice:

'REF doesn't say, “Did you do that work between nine to five?" It says, “Did you do that work?" So you cannot change that '.

(Yvonne, University Z)

This quote is particularly revealing of the challenge involved in implementing gender equality initiatives (core hours) in the face of institutional culture, which in this case is depicted as an immoveable entity ('you cannot change that'). Also interesting is how the conundrum of remasculinisation is being played out through the heroic focus on REF driven metrics and targets around the clock. 
Gender mainstreaming and integrating gender equality into all processes is fundamental [21]. Our respondents display an astute awareness of such covert aspects and how they underwrite institutional discourses of meritocracy:

'I suppose that if there's an element of gender to it then I would say it's probably in the way in which promotions, and I'm not just talking about academia here, now they favour a certain attitude to work, they favour a certain tone and a certain confidence that you find more regularly amongst male colleagues'.

(Lynn, University X)

Participants engaged in the final dissemination seminar considered ways in which the discourse of promotion is in itself self-promotional and individualistic rather than team based- 'I did' rather than 'we did' and the degree to which the reluctance to self-promote may be explained by a 'cultural mismatch' between the act of self-promoting and some of the ways in which female academics are more typically socialised.

The rising popularity of gender bias awareness or unconscious bias training is gathering purchase in HE [69] and surfaces across interview and seminar data. Indeed such awareness training may well increase opportunities to rethink excellence programmes and provide a fitting antidote to the processes of concealment that feed gender denial. Additionally, the increasing demand for such awareness training across academic institutions perhaps signifies a considered and conscious response to the 'entrenchment' of gendered hierarchies. As such, our empirical data and review of the HE context suggests that while gender denial and gendered hierarchies still constitute a challenge (as Broadbridge and Simpson attest), the move on an institutional level towards gender awareness training could prefigure an additional feature of gender and management/leadership research that is rising in prominence-namely challenging hegemonic discourses and cultural practices through a focus on unconscious bias rather than operational procedures. It may be premature and overly optimistic speculation to hope that this heralds a shifting of the tectonic plates.

We must nevertheless acknowledge that our data currently indicate that the more 'overt' barriers relating to institutional practices and behaviours continue to be highly influential in preserving gender inequality, such as the dominance of the self-application route in promotion procedures and the lack of gender diversity on promotion panels. A further interesting barrier highlighted above and in need of interrogation is transparency, which is perhaps most critical in tackling these more overt barriers. Lack of transparency is identified in our study as a significant threat to equality which applies to all aspects of institutional practice (data, processes, procedures) which in turn infiltrates the culture. In our research, women report the prevalence of grace and favour appointments and not 'knowing the rules' of the game as they pertained to senior leadership let alone knowing 'how to play' the game'

Indeed our study theme 'Career path-negotiating the trajectory' was imbued with instances of hidden rules, opacity and shifting sands with respect to how key decisions were made, decisions which impacted individuals' advancement within their institution:

"The roles above head of department, there is no route ... there is no transparency ... almost like a secret society which you might be let into, I've no idea how to get into it."

(Lana, University X)

The quote above attests to the continued influence of secretive gendered cultures in institutional practice, leading to what Broadbridge and Simpson (p. 476) [1] described as 'the numerical dominance of men in senior positions'. However, 'numerical dominance' leads to cultural hegemony whereby the patriarchal vision of reality continues to influence institutional consciousness. Conversely, reversing such numerical dominance via the establishment of 'critical mass' is conceptualized by one respondent as a strategy for combatting patriarchal hegemony and providing an arena for women to raise tensions as legitimate focus for consideration, unencumbered by their minority group status: 
'We do need more women representation in terms of numbers at certain levels I think to help overcome that tension. Because that leads to a greater understanding of what the issues are. I think one of the problems is that if you're in a minority any tensions you might be facing are not considered'.

(Lisa, University X)

For this reason, it could be argued that increasing transparency in institutional practices would be a fitting solution to this barrier. However an interesting paradox occurs when some respondents had clearly benefitted from the 'tap on the shoulder':

'When I first became head of department—so this was 2008 I think—the Vice-Chancellor said to me, "You could be a PVC." And I just went, "Yeah, fine." And walked away. He didn't have to say that, and maybe he says it to everybody, I don't know. But just to plant that seed in somebody's mind. And that's what we can do for everyone. We encourage everybody, whether they're male or female, saying you can do this, don't be afraid'.

(Sandy, University Y)

However, there were other seemingly contradictory accounts that suggest this practice of somewhat covert patronage leads to further prolonging the absence of women, as respondent Lucy argues: 'But it means you're completely invisible' (Lucy, University X). The quandary that presents itself is as follows: when does a supportive intervention focussed on the individual (talent spotting, championing and developing academic women) become a non-equitable behaviour that feeds into the idea that certain women (and men) need to be coaxed out of a fearful, unassertive position into assuming the mantle of senior leadership? Perhaps what is indicated is that interventions focussed on the individual need to acknowledge this tension. Aside from the practice of patronage/sponsorship there are other entrenched traditions within institutions such as population of committees by ex-officio roles and the practice of self-nomination which can perpetuate masculine cultures of leadership ('And it seems to me that men are more likely to self-nominate for positions or recognition', University $X$, Lana) and leave women feeling marginalized, silenced and excluded from these roles.

To summarise both overt and covert barriers can lead to entrenchment of gendered hierarchies and both need addressing but by different mechanisms such that fixing universities rather than fixing women is gaining traction [27]. Karatas-Ozkan and Chell's [33] use of Bourdieu's concept of habitus and field is illuminating as they conclude their 'interrelations demonstrate the complex nature of gender inequalities' (p120). This conclusion lends significant support to and further extends Broadbridge and Simpsons' [1] assertion that gender denial, shored up by the architecture of entrenched gendered discourses continues to be a powerful force. We proffer an additional feature to be considered for future debates: in order to fully address entrenchment we need to critically engage with the thorny issue of the instances when women themselves report benefitting from those non-equitable practices (such as the tap on the shoulder) which perpetuate inequality and to closely interrogate such narratives. A central message emerging here is that dealing with the 'grey spaces' and tensions in women's narratives rather than clear cut binaries will be an enduring challenge in the field.

\subsection{Challenge Notion that Gender Discrimination Is a 'Thing of the Past'}

Given the legacy of Broadbridge and Simpson's overview of the preceding 25 years, it is worth exploring what are some of the shifting priorities in the intervening years since publication of their work. Of the four key challenges they highlight, our research most clearly addresses the 'problem of gender has been solved' and the 'discourse of meritocracy and choice'. Both these notions perpetuate the view that gender discrimination is now outmoded-as very much a phenomenon of earlier eras and no longer a theme of our times. Our research data reveal that promotion and recruitment processes encourage discourses of meritocracy and choice by way of presumed 'objective criteria' which effectively bypass deeper cultural prejudices. The reality is that academic women still find it 
harder to access the prestige required for promotion beyond mid-career [69]. Our research findings expose many tensions and contradictions around personal responsibility for individuals which in turn ties into debates as to whether interventions need to be targeted at the institution or the individual. There is significant variation in the degree to which respondents locate the problem in the institution or in the individual. So while the data indicate selected support for the notion that 'the problem of gender has been solved' with some respondents believing that women have the power to shape their own destiny and overcome obstacles; there is also widespread awareness of how the construct of personal choice continues to be underwritten by gendered power relations [70]. If we are to mount a significant challenge to gender discrimination and the entrenched practices that underwrite it, we need to critically and reflexively engage with the tensions and anomalies that surface in women's narratives.

This vexed question of personal choice resonates well with the body of literature on gendered organisational cultures. As pessimistically observed by Cockburn [71] and Maddock and Parkin [72] these cultures are highly resilient to equality initiatives and self-perpetuate a model of leadership that is masculine, continuing the debate of think leaders, think male [58]. The long term effect of such cultural environments can lead to women feeling ostracised [26] and ultimately disengaged from leadership roles - disengagement which subsequently becomes formulated as personal choice. This cycle perpetuates the discourse of meritocracy and ultimately supports a denial of gender discrimination which impacts negatively on female representation in senior management roles. Embracing plurality in styles of leadership is a significant challenge given our findings that institutional and cultural norms can become internalised and remain undetected. As Lana (University X) posits, a focus on 'fixing' the overt features such as numbers (of women in leadership roles) belies the continued influence of internalized norms and values and stymies the potential of plurality to inform future configurations of leadership. In this respect, if we are to truly in the words of our fourth study theme, challenge ways of knowing, the focus should be not merely on the gender of the leader but on the impact of performing masculine styles of leadership whether by women or men.

'So what we don't want is to fix the issue by putting in a Margaret Thatcher who will simply be a clone of the others but in a slightly different suit. So it's embracing different styles of leadership'.

(Lana, University $\mathrm{X}$ )

A solution, we suggest, is to embrace the diversity of voices, including those that lend support to gendered practices in order to interrogate taken for granted concepts such as 'personal choice'. We acknowledge that this may be an uncomfortable experience, and to be aware of any temptation to iron out tensions and anomalies that we encounter in women's narratives.

\section{Summary and Conclusions}

In summary, our paper has taken up the challenge for further research that Broadbridge and Simpson articulated in their priorities for the future and we have situated this challenge with higher education, a previously overlooked sector despite its key political importance. Our study has broadly lent support to, built on and further enhanced the key challenges identified in their review and indicates that many of the key issues identified in their thematic analysis continue to prevail and thrive in HE institutions. However we would also like to highlight that the gathering purchase of unconscious bias training in HE institutions signifies a substantial challenge to gender denial and the entrenched practices that they suggest have been thus far resistant to interventions. Thus we argue that this represents an additional feature that could rise in prominence in gender equality researchstudies of the effect of unconscious bias training on cultural practices in HE. Indeed, we have sought to demonstrate that a unifying strand in our research has been the exposure of covert institutional practices through clarifying and conceptualizing emerging gendered hierarchies and new forms of gendered power, and revealing hidden, gendered practices and processes currently concealed within norms, customs and values. For this reason, if we really wish to do justice to the concept and practice of 
plurality, it is imperative that future research in this area involves a conscious critique of the prevailing issues (including such notions as academic excellence) and is underpinned by critically reflexive methodologies that reveal how gendered power relations and regimes continue to be written into institutional practices and configurations of senior leadership [73].

Contribution to relevant debates in the field by recourse to empirical data is an especially important practice given our appraisal of the UK HE context and wider observations that gender continues to occupy a precarious and subsidiary position within leadership and management. Thus, we would like to explicitly recommend 'plurality' as a tool for countering some of the key challenges and areas of resistance and in our analysis and conclusions below we offer specific examples of how plurality can be used to good effect. Conversely we are also mindful that plurality can be the proverbial double edged sword when it is used to dilute core values that relate to the standpoint and perspective of women, leading to the abandonment of gender as a coherent category. However, we argue it is possible to reconcile considerations of plurality with a focus on gender, namely how plurality impacts on achievement of gender diversity. In so doing, we will consider the areas in which our findings have added empirical support to Broadbridge and Simpson's original findings, and conversely highlight where our findings indicate additional features that have risen in prominence and which stand to populate the debates of the future.

In this paper we have developed an emerging conceptual framework which we have used to further understand gender inequality in the HE context. We suggest that this model for conceptual framework development has a number of benefits as a heuristic device. This framework: (1) enables us to map disparate elements of what can be a diverse and unpredictable terrain and to identify pertinent interrelationships and emergent new features; (2) assists with the appraisal of how debates are contributing to progress in the field, potentially identifying areas of stasis/stagnation; (3) offers a way of structuring empirical findings from future research projects which in turn has potential to contribute to the development of the framework. The framework constitutes a substantive contribution to the field and has potential for a genuine assessment of the progress that is being made in achievement of gender diversity. Importantly, we have demonstrated that Broadbridge and Simpson's thematic insights - can potentially be transposed to different organisational contexts and disciplines-in this case $\mathrm{HE}$ in the UK-and when combined with empirical findings has potential to generate any number of heuristic frameworks. We therefore commend it as a tool for both informing future debates and reflexively appraising future empirical research. As a final recommendation-or plea-we would ask future researchers in the field of gender to consider our model for developing conceptual frameworks with the express intention of honouring Broadbridge and Simpson's recommendation to 'reveal the hidden aspects of gender and the processes of concealment within norms, practices and values'. Unless we accept the challenge-and it is a substantial challenge-to research that which is concealed, we run the risk of cementing gendered hierarchies and silencing dissenting voices.

Author Contributions: All authors made equal contributions to the research; Burkinshaw and Cahill are joint lead authors.

Conflicts of Interest: The authors declare no conflict of interest.

\section{References}

1. Broadbridge, A.; Simpson, R. 25 Years On: Reflecting on the Past and Looking to the Future in Gender and Management Research. Br. J. Manag. 2011, 22, 470-483. [CrossRef]

2. ECU. Equality in Higher Education: Statistical Report 2016; Equality Challenge Unit: London, UK, 2016.

3. Jarboe, N. WomenCount: Leaders in Higher Education 2016; KPMG: London, UK, 2016.

4. EHRC. Sex and Power. London. 2011. Available online: https://www.equalityhumanrights.com/sites/ default/files/sex_and_power_2011_gb_2_.pdf (accessed on 31 May 2018).

5. Leathwood, C.; Read, B. Gender and the Changing Face of Higher Education-A Feminized Future? Open University Press: Maidenhead, UK, 2009.

6. Jarboe, N. WomenCount: Leaders in Higher Education 2013; KPMG: London, UK, 2013. 
7. BIS. Contribution of UK Universities to National and Local Economic Growth; Department for Business, Innovationa and Skills: London, UK, 2015.

8. Warwick, D. Women and Leadership: A higher education perspective. In A Speech Given at the Barbara Diamond Memorial Lecture 17 March 2004; Universities UK: London, UK, 2004.

9. Ross, R.; Schneider, R. The Rationale for Equality and Diversity: How Vice Chancellors and Principals Are Leading Change; Equality Challenge Unit: London, UK, 2014.

10. Tiessen, R. Everywhere/Nowhere. Gender Mainstreaming in Development Agencies; Kumarian Press: Boulder, CO, USA, 2007.

11. Mushaben, J. Girl Power, Mainstreaming and Critical Mass: Women's Leadership and Policy Paradigm Shift in Germany's Red-Green Coalition, 1998-2002. J. Women Politics Policy 2005, 27, 135-161. [CrossRef]

12. Morley, L. Organising Feminisms: The Micropolitics of The Academy; Macmillan Press: Basingstoke, UK, 1999.

13. Rice, C. 6 Steps to Gender Equality: How Every University Can Get More Women to the Top and Why They Should; Science in Balance Group: Tromso, Norway, 2014.

14. Department for Business, Innovation and Skills. The Business Case for Equality and Diversity: A Survey of the Academic Literature; UK Government: London, UK, 2013.

15. CIPD. Managing Diversity: Linking Theory and Practice to Business Performance; Chartered Institute of Personnel and Development: London, UK, 2005.

16. Coleman, M. Women at the Top: Challenges, Choices and Change; Palgrave MacMillan: Basingstoke, UK, 2011.

17. Vinnicombe, S.; Sealy, R. Women on boards in the UK: Accelerating the pace of change? In Getting Women on to Corporate Boards: A Snowball Starting in Norway; Machold, S., Huse, M., Hansen, K., Brogi, M., Eds.; Edward Elgar: Gloucester, UK, 2013.

18. Bagilhole, B.; White, K. Gender, Power and Management [Electronic Resource]: A Cross-Cultural Analysis of Higher Education; Palgrave Macmillan: Basingstoke, UK, 2011.

19. Burkinshaw, P. Higher Education, Leadership and Women Vice Chancellors: Fitting in to Communities of Practice of Masculinities; Palgrave Macmillan: Basingstoke, UK, 2015.

20. Benschop, Y.; Brouns, M. Crumbling Ivory Towers: Academic Organizing and its Gender Effects. Gend. Work Organ. 2003, 10, 194-212. [CrossRef]

21. Van den Brink, M.; Benschop, Y. Gender in Academic networking: The Role of Gatekeepers in Professorial Recruitment. J. Manag. Stud. 2014, 51, 460-490. [CrossRef]

22. Van den Brink, M.; Benschop, Y. Gender practices in the construction of academic excellence: Sheep with five legs. Organisation 2012, 19, 507-524. [CrossRef]

23. Bird, S.R. 'Unsettling universities' incongruous, gendered bureaucratic structures: A case study approach. Gend. Work Organ. 2011, 18, 202-230. [CrossRef]

24. David, M. Feminisms, Gender and Universities: Politics, Passion and Pedagogies; Ashgate Publishing: Farnham, UK, 2014.

25. Morley, L. Misogyny posing as measurement: Disrupting the feminisation crisis discourse. Contemp. Soc. Sci. 2011, 6, 223-235.

26. Priola, V. Being female doing gender. Narratives of women in education management. Gend. Educ. 2007, 19, 21-40. [CrossRef]

27. Chesterman, C.; Ross-Smith, A.; Peters, M. “"Not doable jobs!” Exploring senior women's attitudes to academic leadership roles. Women's Stud. Int. Forum 2005, 28, 163-180. [CrossRef]

28. Ford, J.; Harding, N. Get back into that kitchen, woman: Management conferences and the making of the female professional worker. Gend. Work Organ. 2010, 17, 503-520. [CrossRef]

29. Burkinshaw, P.; White, K. Fixing the women or fixing universities: Women in HE leadership. Adm. Sci. 2017, 7, 30. [CrossRef]

30. Clarke, C.; Knights, D. Reconfiguring resistance: Gendered subjectivity and New managerialism in UK Business Schools. In Organisation Studies Summer Workshop: Resistance, Resisting and Resisters in and Around Organisations; Open University Business School: Corfu, Greece; Milton Keynes, UK, 2014.

31. Ford, J.; Collinson, D. In Search of the Perfect Manager? Work-life balance and managerial work. Work Employ. Soc. 2011, 25, 257-273. [CrossRef]

32. Aaltio, I.; Mills, A.; Helms Mills, J. Exploring gendered organisational cultures. Cult. Organ. 2002, 8, 77-79. [CrossRef]

33. Alvesson, M.; Billing, Y.D. Understanding Gender and Organizations; SAGE: Los Angeles, CA, USA, 2009. 
34. Mackenzie Davey, K. Women's Accounts of Organizational Politics as a Gendering Process. Gend. Work Organ. 2008, 15, 650-671. [CrossRef]

35. Karatas-Ozkan, M.; Chell, E. Gender Inequalities in Academic Innovation and Enterprise: A Bourdieuian Analysis. BJM 2015, 26, 109-125. [CrossRef]

36. Fitzgerald, T. Troubling leadership? Gender, leadership and higher education. In Proceedings of the AARE Conference, Hobart, Australia, 30 November 2011.

37. Haake, U. Doing Leadership in Higher Education: The gendering process of leader identity development. Tert. Educ. Manag. 2009, 15, 291-304. [CrossRef]

38. Sealy, R.H.V.; Singh, V. The Importance of Role Models and Demographic Context for Senior Women's Work Identity Development. Int. J. Manag. Rev. 2010, 12, 284-300. [CrossRef]

39. Wajcman, J. Managing Like a Man: Women and Men in Corporate Management; Polity: Cambridge, UK, 1998.

40. Ely, R.; Ibarra, H.; Kolb, D. Taking gender into account: Theory and design for women's leadership development programmes. Acad. Manag. Learn. Educ. 2011, 10, 474-493. [CrossRef]

41. Ryan-Flood, R.; Gill, R. Secrecy and Silence in the Research Process: Feminist Reflections; Routledge: Abingdon, UK; Oxon, UK; New York, NY, USA, 2010.

42. Sprague, J. The Academy as a Gendered Institution; Warwick University Feminism Conference: Warwick, UK, 2013.

43. O'Connor, P. Good jobs - but places for women? Gender Educ. 2015, 27, 304-319. [CrossRef]

44. Schiebinger, L.; Schraudner, M. Interdisciplinary Approaches to Achieving Gendered Innovations in Science, Medicine, and Engineering. Interdiscip. Sci. Rev. 2011, 36, 154-167. [CrossRef]

45. Van den Brink, M.; Benschop, Y. Slaying the seven-headed dragon: The quest for gender change in academia. Gend. Work Organ. 2012, 19, 71-92. [CrossRef]

46. Cabrera, E.F. Protean Organizations: Reshaping Work and Careers to Retain Female Talent. Career Dev. Int. 2009, 14, 186-201. [CrossRef]

47. Eagly, A.H.; Carli, L.L. Women and the labyrinth of leadership. Harv. Bus. Rev. 2007, 85, 63-71. [CrossRef]

48. Ford, J. Discourses of Leadership: Gender, Identity and Contradiction in a UK Public Sector Organization. Leadership 2006, 2, 77-99. [CrossRef]

49. Carter, M.L.; Silva, C. The Myth of the Ideal Worker: Does Doing All the Right Things Really Get Women Ahead? In The Promise of Future Leadership: Highly Talented Employees in the Pipeline; Catalyst: New York, NY, USA, 2011.

50. Brooks, A.; Mackinnon, A. Gender and the Restructured University: Changing Management and Culture in Higher Education; Society for Research into Higher Education \& Open UP: Buckingham, UK, 2001.

51. Van den Brink, M. Scouting for talent: Appointment practices of women professors in academic medicine. Soc. Sci. Med. 2011, 72, 2033-2040. [CrossRef] [PubMed]

52. Nielsen, M.W. Limits to meritocracy? Gender in academic recruitment and promotion policies. Sci. Public Policies 2016, 43, 386-399. [CrossRef]

53. Van der Lee, R.; Ellemers, N. Gender contributes to grant funding success in The Netherlands. Proc. Natl. Acad. Sci. USA 2015, 112, 12349-12353. [CrossRef] [PubMed]

54. O'Connor, P.; Montez López, E.; O’ Hagan, C.; Wolffram, A.; Aye, M.; Chizzola, V.; Mich, O.; Apostolov, G.; Topuzova, I.; Sağlamer, G.; et al. Micro-political practices in higher education: A challenge to excellence as a rationalising myth? Crit. Stud. Educ. 2017, 1-17. [CrossRef]

55. Catalyst. The Double-Bind Dilemma for Women in Leadership: Damned if You Do, Doomed if You Don't; Catalyst: New York, NY, USA, 2007.

56. Francis, B. Re/theorising gender: Female masculinity and male femininity in the classroom? Gend. Educ. 2010, 22, 477-490. [CrossRef]

57. Gherardi, S.; Poggio, B. Gendertelling in Organizations: Narratives from Male-Dominated Environments; Marston Book Services: Abingdon, UK, 2007.

58. Acker, S. Gendered games in academic leadership. Int. Stud. Sociol. Educ. 2010, 20, 129-152. [CrossRef]

59. Eveline, J. Woman in the ivory tower: Gendering feminised and masculinised identities. J. Organ. Chang. Manag. 2005, 18, 641-658. [CrossRef]

60. Schein, V.E.; Mueller, R.; Lituchy, T.; Liu, J. Think manager-Think male: A global phenomenon? J. Organ. Behav. 2006, 17, 33-41. [CrossRef] 
61. Cunliffe, A.L. The philosopher leader: On relationalism, ethics and reflexivity-A critical perspective to teaching leadership. Manag. Learn. 2009, 40, 87-101. [CrossRef]

62. Kondo, D. Crafting Selves, Power, Gender E Discourses of Identity in a Japanese Workplace; Chicago University Press: Chicago, IL, USA, 1990.

63. Hall, S. Foucault: Power, Knowledge and Discourse. In Discourse, Theory and Practice: A Reader; Wetherell, M., Taylor, S., Yates, S., Eds.; Sage/OU: London, UK, 2001; pp. 72-81.

64. McAdams, D. The Stories We Live by: Personal Myths and the Making of the Self; The Guildford Press: New York, NY, USA, 1993.

65. McAdams, D.; Josselson, R.; Lieblich, A. Turns in the Road: Narrative Studies of Lives in Transition; American Psychological Association: Washington, DC, USA, 2001.

66. McLeod, C.; O’Donohoe, S.; Townley, B. Pot noodles, placements and peer regard: Creative career trajectories and communities of practice in the British advertising industry. Br. J. Manag. 2010, 22, 114-131. [CrossRef]

67. Crossley, M. Introducing Narrative Psychology: Self, Trauma and the Construction of Meaning; Open University Press: Buckingham, UK, 2000.

68. Ryan, M.K.; Haslam, S.A. The Glass Cliff: Evidence that Women are Over-Represented in Precarious Leadership Positions. Br. J. Manag. 2005, 16, 81-90. [CrossRef]

69. Erkut, S.; Kramer, V.W.; Konrad, A.M. Critical Mass: Does the Number of Women on a Corporate Board Make a Difference? In Women on Corporate Boards of Directors: International Research and Practice; Vinnicombe, S., Singh, V., Burke, J., Bilimoria, D., Huse, M., Eds.; Edward Elgar: Cheltenham, UK, 2008; pp. 222-232.

70. Kandiko Howson, C.B.; Coate, K.; de St Croix, T. Mid-career Academic Women: Strategies, Choices and Motivation. In Small Development Projects; Leadership Foundation for Higher Education.; Kings Learning Institute, Kings College: London, UK, 2015.

71. Cockburn, C. In the Way of Women: Men's Resistance to Sex Equality in the Workplace; Macmillan: London, UK, 1991.

72. Maddock, S.; Parkin, W. Gender Cultures: Women's Choices and Strategies at Work. Women Manag. Rev. 1993, 8, 3-9. [CrossRef]

73. Acker, J. Inequality Regimes Gender, Class, and Race in Organizations. Gender Soc. 2006, 20, $441-464$. [CrossRef]

(C) 2018 by the authors. Licensee MDPI, Basel, Switzerland. This article is an open access article distributed under the terms and conditions of the Creative Commons Attribution (CC BY) license (http://creativecommons.org/licenses/by/4.0/). 